\title{
Role of the Natural and Social Sciences in Cop21 Implementation: Success or Failure
}

\author{
Jan-Erik Lane ${ }^{1}$ \\ ${ }^{1}$ Fellow with Public Policy Institute in Belgrade, Serbia \\ Correspondence: Jan-Erik Lane, 10 Charles Humbert, 1205 Geneva, Switzerland.
}

Received: March 30, 2016

Accepted: August 9, 2016

Online Published: August 17, 2016

doi:10.5430/jms.v7n3p23

URL: http://dx.doi.org/10.5430/jms.v7n3p23

\begin{abstract}
Hitherto, the natural sciences have furnished the essential informatio for the COP21 process, measuring the increase in greenhouse gases (GHG) and modelling the impact upon global temparatures in different scenarios of CO2:s in the atomosphere. There is still uncertainty among scientists about how strong the global warming trend is as well as how many degrees of alternative temperature rise are likely and where on the Planet. Still some scientist came forward now and deny truth of the theory of climate. However, just as important that the natural sciences deliver unbiased data and a variety of predictions is the recogniton of the major tasks of the social sciences in the COP21 framework. The COP21 will be the biggest project ever undertaken in global governancem with a budget ceiing of 100 billion dollars every year in the first half of the 21 rst cenury. Implementation theory predicts complexity, reversals and the strategic handling of information. Implementation success is in no way guaranteed as each government must act in a country specific situation. Will money be forthcoming in time as well as used efficiently? Is the Stern Super Fund the powerful tool promised to poor countries for new and innovative energy policies? The purpose here is to show that most countries have an increasing lin between GDP and GHC:s as well as that they are much dependent upon fossil fuels and wood coal.
\end{abstract}

Keywords: the two perspectives on global warming (GW), natural sciences' uncertainty, social scienecs scepticim towards global coordination, implementation theory, outputs versus outcomes, decentralised olicy approach, weak oversight in global governance, energy mixes, GDP-GHG(CO2) link

\section{Introduction}

Economist J. Sachs has launched a coherent call for the world to move towards sustainable development, based on decarbonisation of the energy systems of countries (http://jeffsachs.org/2015/08/sustainable-development-for-humanitys-future/). He has correctly emphasized the close link between economic development or growth and the massive use of fossil fuels as energy sources during the last 20 years, resulting in the enormous expansion of GHG emissions. The Figure 1 displays this link.

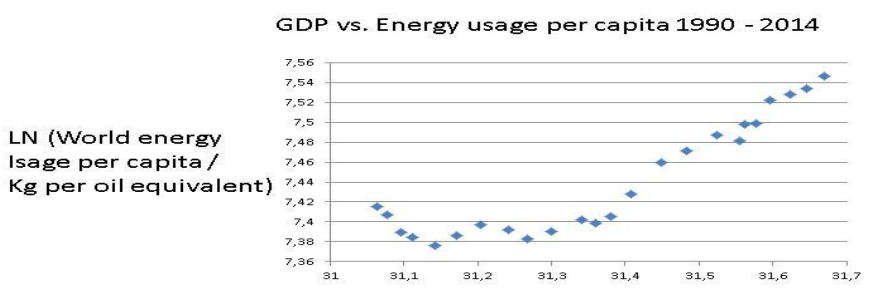

LN (World GDP in constant value 2005 USD)

Figure 1. Economic development and energy consumption per capita 
However, given this close links between GDP, energy consumption and emissions, how can the countries of the world achieve decarbonisation without hampering economic development or growth? What is the country link between GDP and GHG emissions? It depends upon the nation in question!

The global warming process is already going on and proceeds seemingly unstoppably, involving inter alia larger climate swings, deforestation, desertification, ocean acidification and rising sea levels. But the natural sciences do not really know whether it is an irreversible transformation of Planet Earth, or where it could be stopped, and if so where: $+1,5,+2,+2,7,+4$, and +6 , which last figure would actually be the end of a global catastrophe.

Looking at COP21 in terms of implementation theory, the distinction between policy outputs and outcomes is crucial, as several programs can be started domestically or/and internationally, but they do not promote the main COP21 objectives namely decarbonisation. The technology of accomplishing decarbonisation (halting $\mathrm{CO} 2$ advances, cutting CO2:s by $40 \%$, complete decarbonisation by 2075) is far from known fully and with certainty, especially as there is the very important restraint of not hurting economic development in Third World countries or growth in advanced countries.

It is now argued that the global increase in GHG has stalled and that the dire link between GDP growth and CO2 emission increase has been undone in a few counytries. Yet, merely halting the growth of emissions will not be enough, as the level of yearly emissions stays at an enormous size. What is crucial is the undoing of the close link between energy consumption and GHG emissions. The emissions result primarily from energy use, especially the burning of fossil fuels or biomass and waste materials, and only secondarily from economic activities or development by means of electricity consumption and transportation activities. Economic growth that uses carbon neutral energy would reduce global warming. But this is a utopian goal for the entire global economy. There is a lot of talk about emissions trading and energy taxes, but the outcomes have simply not matched expectations.

The specific country strategies to enhance COP21 will be framed, depending upon their energy pattern in usage, Thus, the governments, the IGO:s and NGO:s and other experts on climate change have to realize that halting or reducing the emission of GHG:s must involve costs. There are simply not enough alternative energy sources or innovations in renewables to draw upon, at the moment. Some countries will ask for special delays, others will call for economic assistance or compensation and some may even decide to promise but later renege. What is involved in this trade-off between reduction of greenhouse gases on the one hand and economic development or growth on the other hand? This article portrays this connection by means of a few figures on a key countries. The closer the link between GDP and emissions is, the more painful or costly will the transition to a stage with massive reduction of emissions be. And the more a country is extremely dependent upon fossil fuels or wood coal, the more it has to change.

\section{Greenhouse Gases: Role of Energy}

Greenhouse gases (GHG) contribute to the so-called greenhouse effect, which boils down to continuous overall warming of the Planet Earth. Atmospheric gases trap electromagnetic radiation from the sun that would otherwise have been reflected back out into space. These greenhouse gases include: methane, nitrous oxide, carbon dioxide, hydro fluorocarbons (HFCs), per fluorocarbons (PFCs), and sulphur hexafluoride (SF6). But these gases make up only a small fraction of the gases of the atmosphere. Here we focus upon the CO2:s (Figure 2).

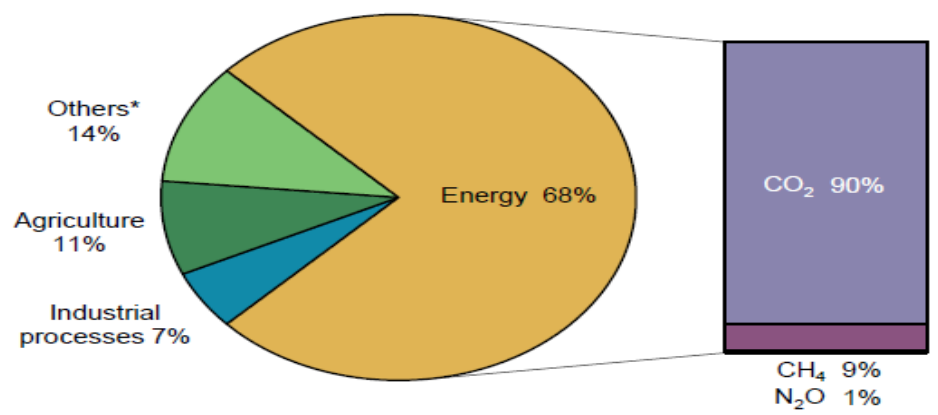

\footnotetext{
* Others include large-scale biomass burning, post-burn decay, peat decay, indirect $\mathrm{N}_{2} \mathrm{O}$ emissions from non-agricultural emissions of $\mathrm{NO}_{x}$ and $\mathrm{NH}_{3}$, Waste, and Solvent Use.

Source: IEA estimates for $\mathrm{CO}_{2}$ from fuel combustion and EDGAR 4.3.0/4.2 FT2010 for all other sources, (see Part III).
}

Figure 2. From Energy to GHC:s and CO2:s 
In the first rounds of implementation of COP21, it is logical to focus on the $\mathrm{CO} 2$ emissions, but methane emissions may become a big headache later on.

Globally speaking, more than 80 per cent of the energy consumed daily is derived from the burning of fossil fuels. How fast can this be changed and what could be the economic costs of decarbonisation? Countries can attempt to meet their obligations in the COP21 Agreement by decarbonisation, lower economic growth or more energy efficiency. New technology and innovations will be crucial, not only in small scale endeavours but used massively. We wish to find out below is how countries vary in terms of their energy consumption and what their degrees of freedom in policy-making could be, given the restriction upon decarbonisation, namely that economic development or growth must not be hurt in any way.

Speaking with economist Sachs, one can only say that decarbonisation will be hard to come by, especially for countries with little hydro or nuclear power. When the requirements of sustainable development collide with conventional economic growth, something has to give. It is not likely that decarbonisation will trump economic development, at least not enough to avoid the $+2,7,+4$ scenarios for example. He states: "Economic development, social inclusion, and environmental sustainability are the three tenets underpinning the forthcoming post-2015 development agenda, a once in a generation opportunity to put mankind on the path to a sustainable growth model." But stylised energy projections defy Sachs' wishful thinking.

Fighting global warming involves reflecting upon several measures, as with the COP21 conference in Paris, including:

- Slowing population growth

- Changing agricultural production modes

- Water recycling and waste treatment

- Ocean protection

- Changes in energy consumption: "decarbonisation"

- Stopping deforestation and protecting rain forests.

Although energy is far from the only source of greenhouse gases, it is the single largest one. Energy use crops up in all forms of activities most often with an economic element: industry, transportation - land, sea, air, housing and commerce as well as food production and agriculture. The implementation of the COP Agreement can only succeed if coal is significantly reduced in electricity production and petroleum decreased in transportation. However, the officially stylised projections point to an altogether different world in 20-30 years.

The predictions found with all energy companies and agencies will when true undo the implementability of COP21. The main implications are that the use of coal in electricity generation must be reduced and coal power stations be equipped with filters. Moreover, the employment of petroleum products must be decreased in transportation: land, sea and air.

The COP21 Agreement in 2015 at Paris calls for implementation in various stages. The guidelines and their oversight are vague, as policy implementation is to be carried out by the national government or signing states. Here is where the social sciences come in; How is this gigantic policy implementation to be handled?

\section{Top-down versus Bottom-up Implementation of International Agrrements}

Drawing upon established implementation theory (Pressman and Wildavsky, 1984), one may ask what approach is suitable for the effective implementation of COP21, underlining not outputs like carbon tax or emission trading but real outcomes, such as diminishing the $\mathrm{CO} 2$ in the atmosphere. It is obvious that $\mathrm{CO} 21$ is biased against a top-down approach, reflecting the weak governance typical of global coordination. Thus, the national governments are to do the much needed work to achieve decarbonisation, followed by some oversight and reporting to international meetings. But can this decentralised approach work for all states?

It should be pointed out that some $25 \%$ of the signing states in Paris do not perform in such a manner that they can conduct any climate change policy on their own. They are ripped apart by civil war, terrorism, corruption or simple lack of resources as well as law and order. Perhaps their governments are eyeing the Stern Super Fund that puts the financial burden on the West for promoting energy changes in several Third World countries. Will not such money be embezzled?

Now, bottom-up implementation may not amount to much implementation at all, as local or regional incentives in the world system of states include opportunism with guile, strongly favouring defection strategies in global coordination. 
To put it bluntly, states can do what they want under COP21, including reneging. The enforcement mechanism outlined in COP21 is too amorphous and lacks strength.

The COP21 Agreement gives the flawed impression that all states face the sane conditions for decarbonisation. Let me show below that countries differ enormously on the two fundamental parameters:

$<$ GDP-GHG link, energy pattern>,

which has a strong impact upon policy implementation and the likelihood of implementation success/failure.

\section{Country Predicaments for Cop21 Policy-Making: Some Examples}

Basically, it is up to each country to start implementing COP21, at least as late as 2020. The more reliant upon coal for electricity and petroleum for transportation they are, the more difficult and costly will be the implementation process. The oversight of the COP21 is so weak that one may speak of "bottom-up" implementation instead of "top-down" implementation. The plaans for a top secetariat speak of data gathering, country visits and more conferences every year. The revolutionary insights in the innovative social sciences and economics concerning asymmetric information ("lying"), hidden actions and opportunistic motivation have not come across to the framers of COP21.

\subsection{East Asia}

One may find that the emissions of GHG:s follows economic development closely in many countries. The basic explanation is population growth and GDP growth - more people and higher life style demands. Take the case of China, whose emissions are the largest in the world, totally speaking (Figure 3).

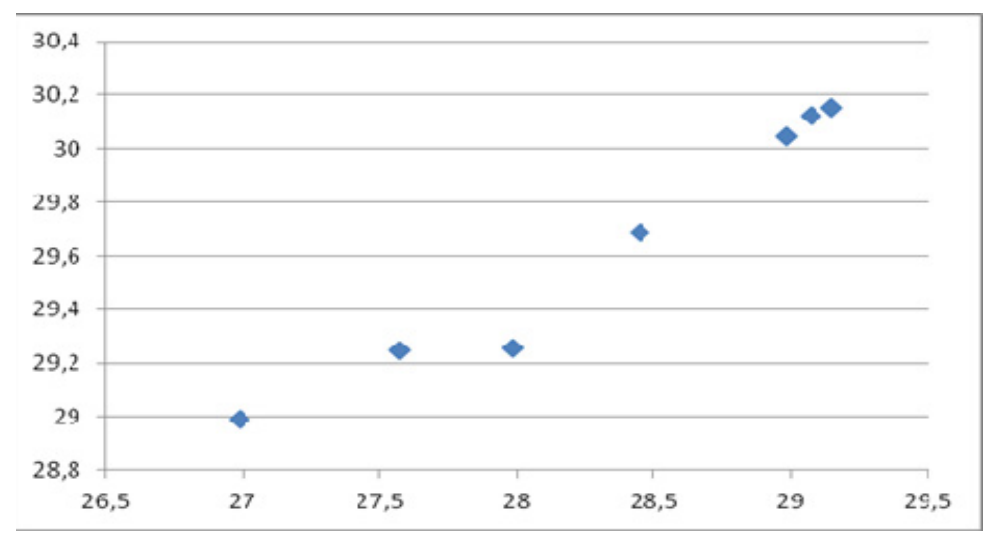

Figure 3. CHINA: LN (GHG / Kg CO2 eq and LN (GDP / Constant Value 2005 USD)

The sharp increase in GHG:s in China reflects not only the immensely rapid industrialization and urbanization of the last 30 years, but also its problematic energy mix (Figure 4).

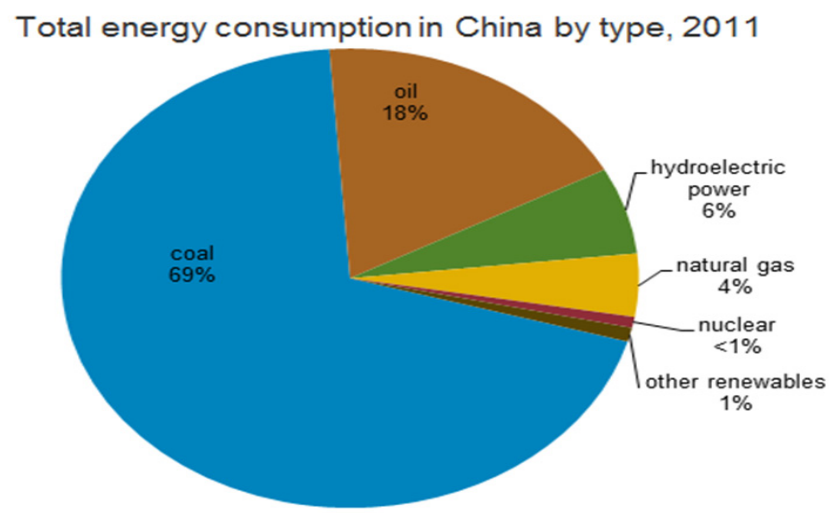

eia Source: U.S. Energy Information Administration International Energy Statistics.

Figure 4

Almost 70 per cent of the energy consumption comes from the burning of coal with an additional 20 per cent from other fossil fuels. The role of nuclear, hydro and other renewable energy sources is very small indeed. This makes 
China very vulnerable to demands for cutting GHG emissions: other energy sources or massive installation of highly improved filters?

It should be pointed out that several small countries have much higher emissions per capita than China. This raises the enormously difficult problematic of fair cuts of emissions. Should the largest polluters per capita cut most or the biggest aggregate polluters? At COP21 this issue was resolved by the creation of a super fund to assist energy transition and environment protection in developing counties, as proposed by economist Stern (2007)

One may find a close link between GDP and emissions also in countries with an advanced economy. See Figure 5 for South Korea.

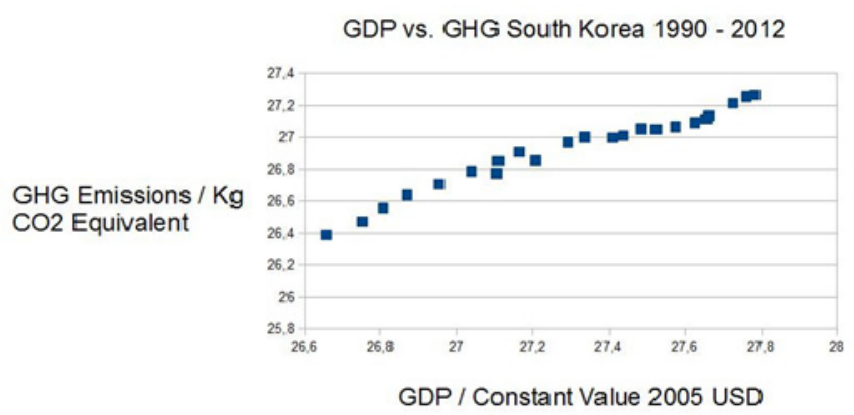

Figure 5. South Korea: LN (GHG / Kg CO2 eq and LN (GDP / Constant Value 2005 USD)

Lacking much hydro power, South Korea has turned to fossil fuels for energy purposes, almost up to 90 per cent (Figure 6). It differs from China only in the reliance upon nuclear power, where the country is a world leader in plant constructions. Reducing its hefty GHG emissions, South Korea will have to rely more upon renewable energy sources, as well as reducing coal and oil for imported gas or LNGs.

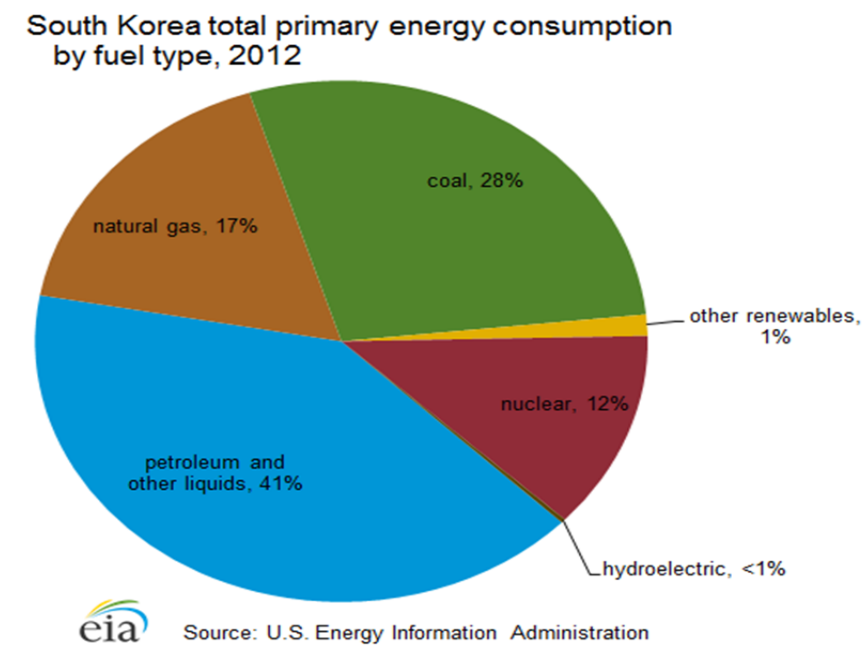

Figure 6

Japan has a rather different situation in that it is no longer willing to rely much upon atomic power. Its emissions have gone done recently, but seem to be on the rise again (Figure 7). 


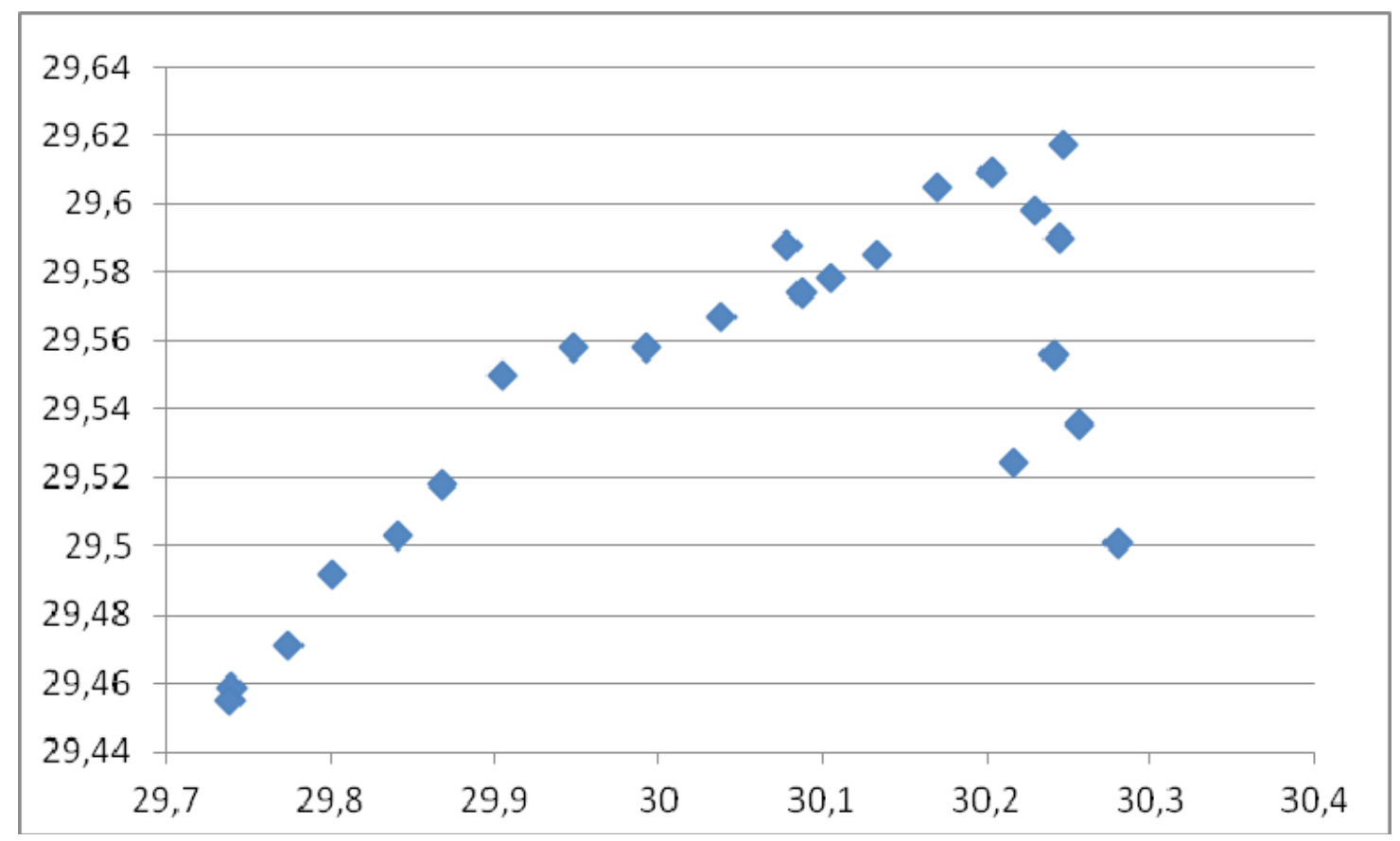

Figure 7. Japan: LN (GHG / Kg CO2 eq and LN (GDP / Constant Value 2005 USD)

The decrease in emissions for Japan reflects the country's post-industrial developments. Production sites have been moved out of Japan with heavy investments in other Asian countries as well as the EU and the US. Yet, Japan will still need massive amounts of energy (Figure 8). After the Fukushima disaster, it operates few major nuclear power plants.

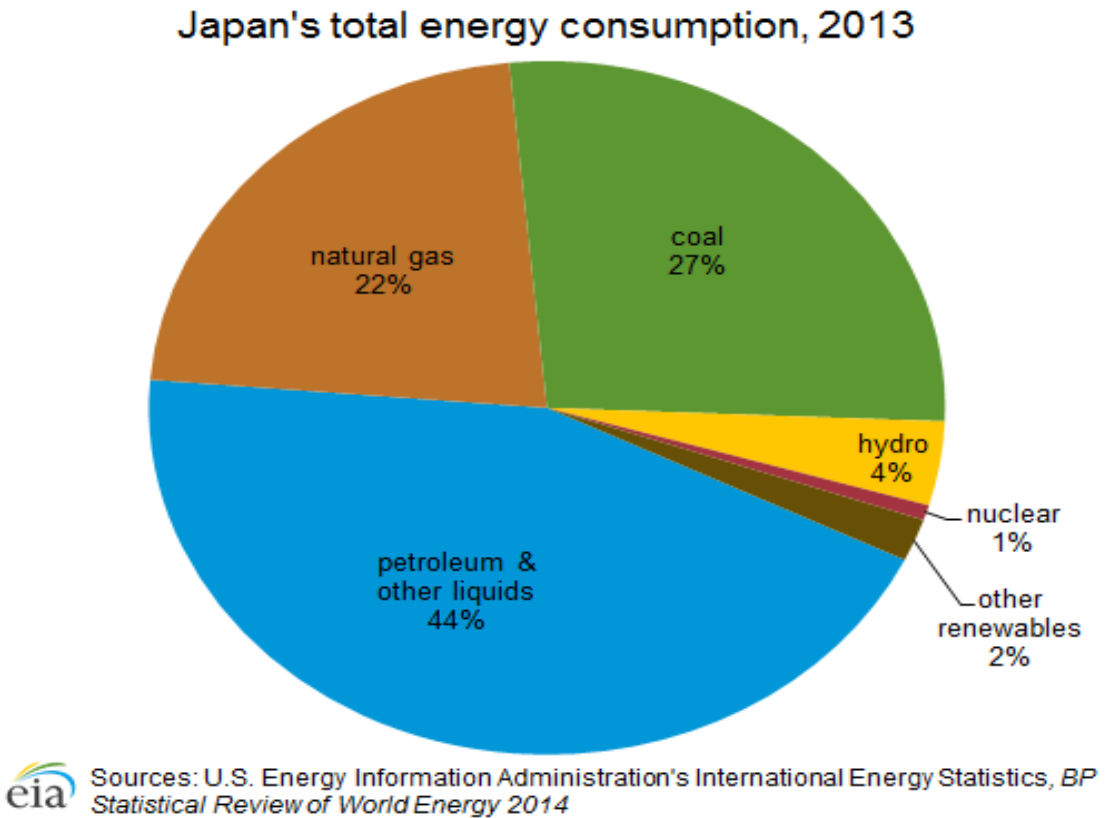

Figure 8

As Figure 8 shows, Japan is very dependent upon fossil fuels for generating electricity and transportation, especially when nuclear power is no longer a major option with one nuclear power plant operating now in Japan. 


\subsection{South Asia}

India will certainly appeal to the same problematic, namely per capita or aggregate emissions. The country is even more negative than China to cut GHG emissions, as it is in an earlier stage of industrialization and urbanization. Figure 8 shows the close connection between emissions and GDP for this giant nation.

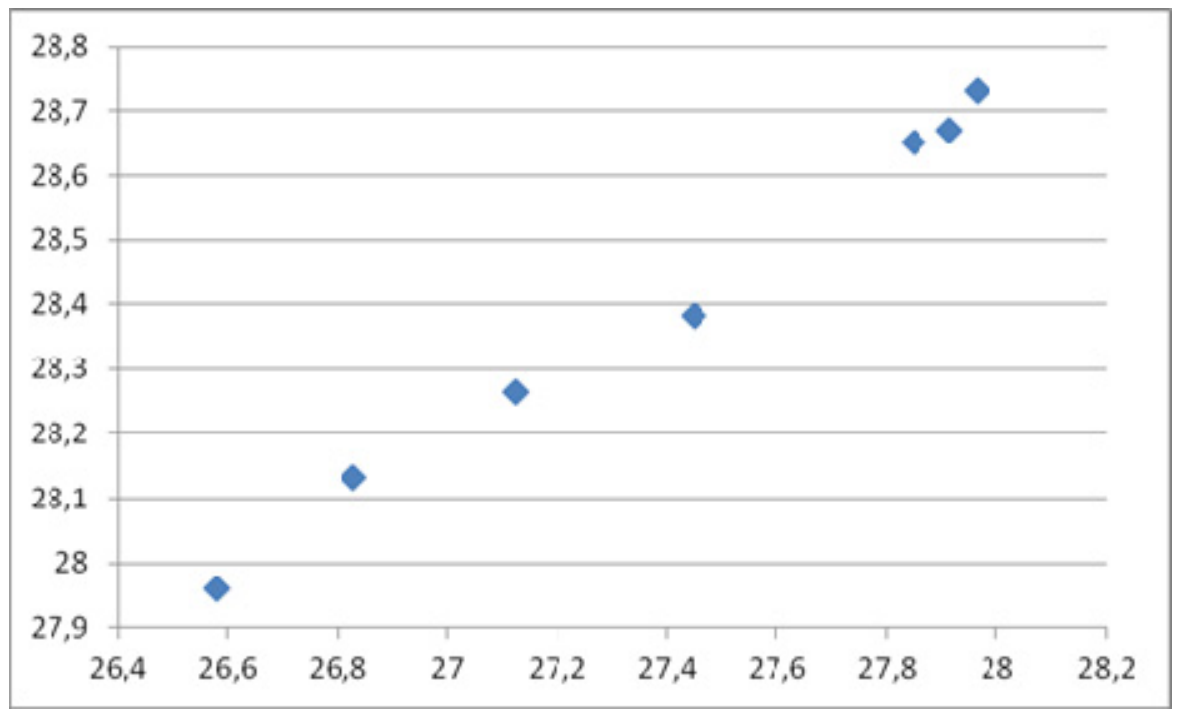

Figure 9. India: LN (GHG / Kg CO2 eq and LN (GDP / Constant Value 2005 USD)

India needs cheap energy for its industries, transportation and heating (Figure 9) as well as electrification. From where will it come? India has water power and nuclear energy, but relies most upon coal, oil and gas as power source. It has strong ambitions for the future expansion of energy, but how is it to be generated, the world asks. India actually has one of the smallest numbers for energy per capita, although it produces much energy totally. Figure 10 shows its energy mix where renewables play a bigger role than in China.

Total energy consumption in India, 2012

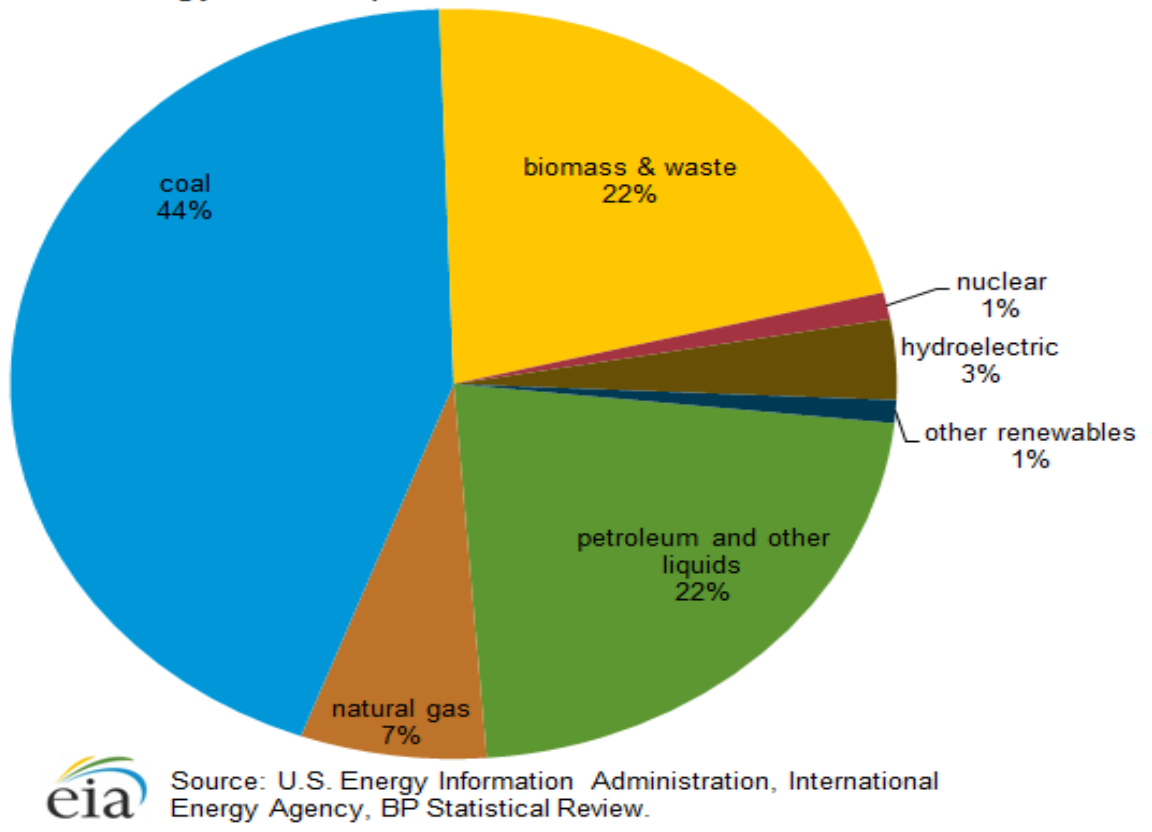

Figure 10

India needs especially electricity, as 300 million inhabitants lack access to it. The country is heavily dependent upon fossil fuels (70 per cent), although to a less extent than China. Electricity can be generated by hydro power and nuclear power, both of which India employs. Yet, global warming reduces the capacity of hydro power and nuclear 
power meets with political resistance. Interestingly, India uses much biomass and waste for electricity production, which does not always reduce GHG emissions. India's energy policy will be closely watched by other governments and NGO:s after 2018.

The above three countries are giant polluters in terms of GHGs. China and South Korea uses mainly fossil fuels for energy consumption, whereas India also employs renewables and hydro power, lacking in the other two.

\subsection{South East Asia}

One may guess correctly that countries that try hard to "catch-up" will have increasing emissions. This was true of China and India. Let us look at three more examples, like e.g. giant Indonesia - now the fourth largest emitter of GHG:s in the world.

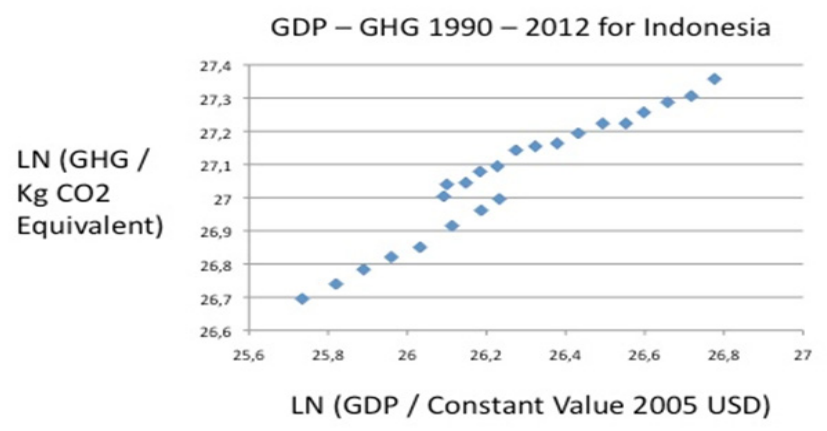

Figure 11. Indonesia: LN (GHG / Kg CO2 eq and LN (GDP / Constant Value 2005 USD)

Indonesia is a coming giant, both economically and sadly in terms of pollution. Figure 27 reminds of the upward trend for China and India. However, matters are even worse for Indonesia, as the burning of the rain forest on Kalimantan augments the GHG emissions very much. Figure 12 presents the energy mix for this huge country in terms of population and territory.

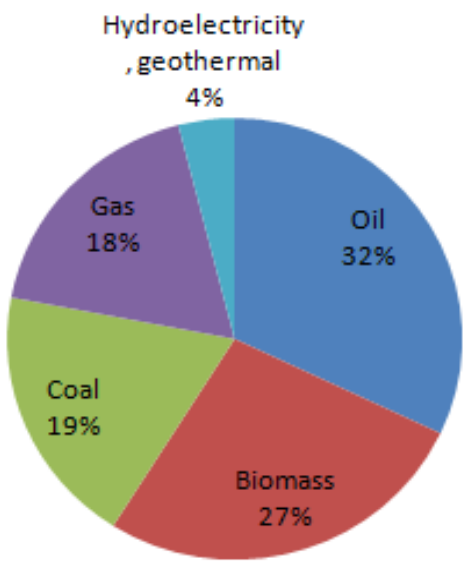

Distribution of Energy Consumption in Indonesia in 2009

Figure 12. (http://missrifka.com/energy-issue/recent-energy-status-in-indonesia.html) 
Only 4 per cent comes from hydro power with 70 per cent from fossil fuels and the remaining 27 per cent from biomass, which alas also pollutes.

Despite its official statements about being a GREEN city, emissions have been going up steadily in Singapore. The GHG:s are very high if related to per capita. Its energy mix is only oil and gas, imported from abroad (Figure 13). Singapore needs lots of electricity to bolster its advanced life style (air conditioning, total waste water cleaning, etc).

\section{GDP vs. GHG emissions}

Singapore $1990-2011$

LN (GHG Emissions /

$\mathrm{Kg} \mathrm{CO} 2$ Equivalent)

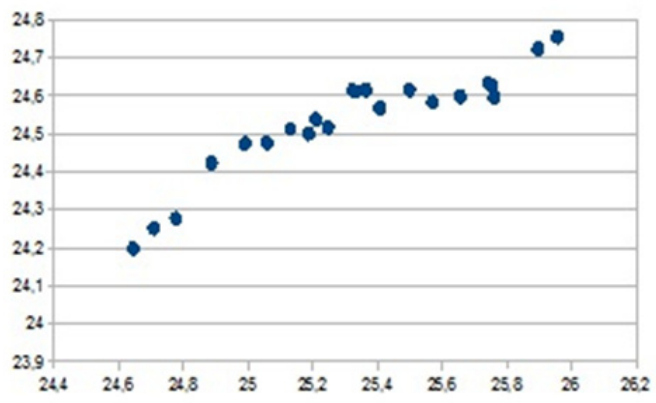

LN (GDP / Constant Value 2005 USD)

Figure 13. GDP-GHC in Singapore

Why would this island state need too much energy, resulting in such an amount of emission of GHG:s? Reply: the need for fossil fuels to generate electricity and make transportation possible. Singapore has a hot climate and handles that with a complete use of air conditioners all over the place. It is also a huge hub for shipping and air travel. It is impossible to generate so much electricity without emissions when using fossils fuels. Singapore has a large oil refinery.Despite its official statements about being a GREEN city, emissions have been going up steadily in Singapore. The GHG:s are very high if related to per capita. Its energy mix is only oil and gas, imported from abroad (Figure 14). Singapore needs lots of electricity to bolster its advanced life style (air conditioning, total waste water cleaning, etc).

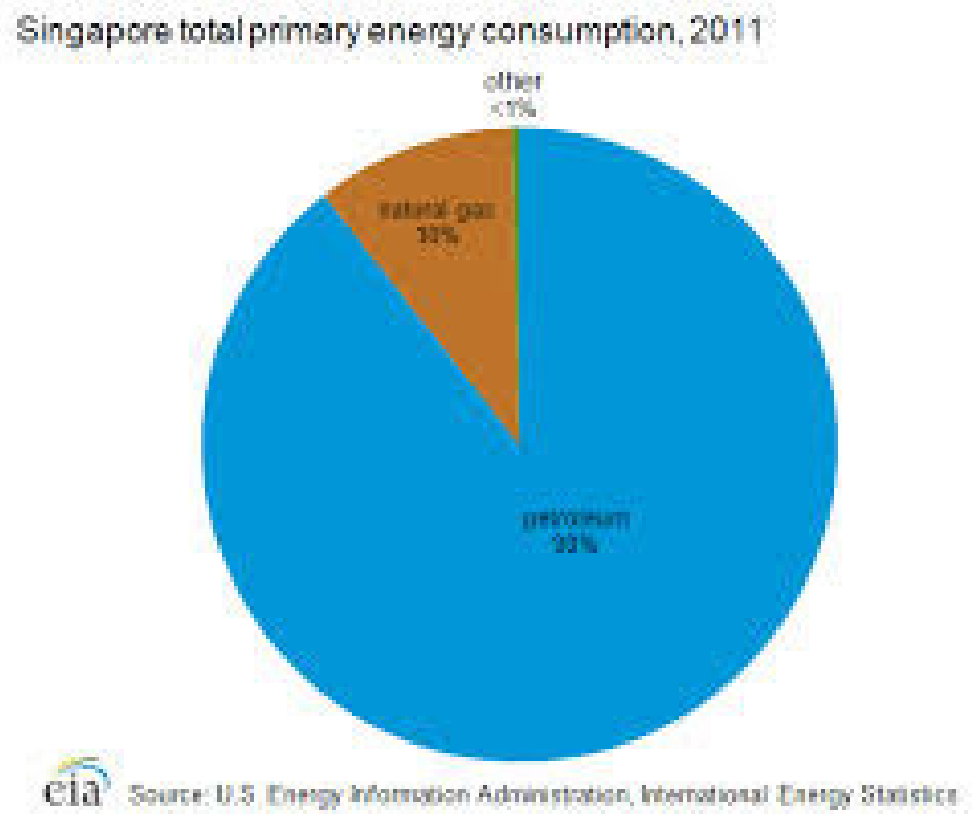

Figure 14 
The need for electriciy is enormous in Singapore: airconditioners, waste tratement, water purification. And it consumes lots of petroleum for transportation.

\subsection{Middle East}

Countries may rely almost exclusively upon petroleum and gas mainly - see Iran in Figure 15 for instance. CO2 emissions have generally followed economic development in this giant country, although there seems to be a planning out recently, perhaps due to the international sanctions against its economy.

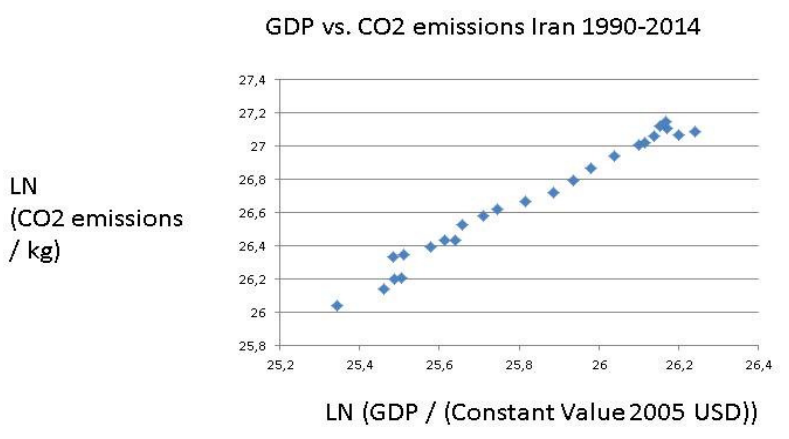

Figure 15. Iran $\left(y=1,2229 x-4,91 ; R^{2}=0,98\right)$

Iran is together with Russia and Qatar the largest owner of natural gas deposits. But despite using coal in very small amounts, its $\mathrm{CO} 2$ emissions are high. Natural gas pollute less than oil and coal, but if released unburned it is very dangerous as a greenhouse gas.

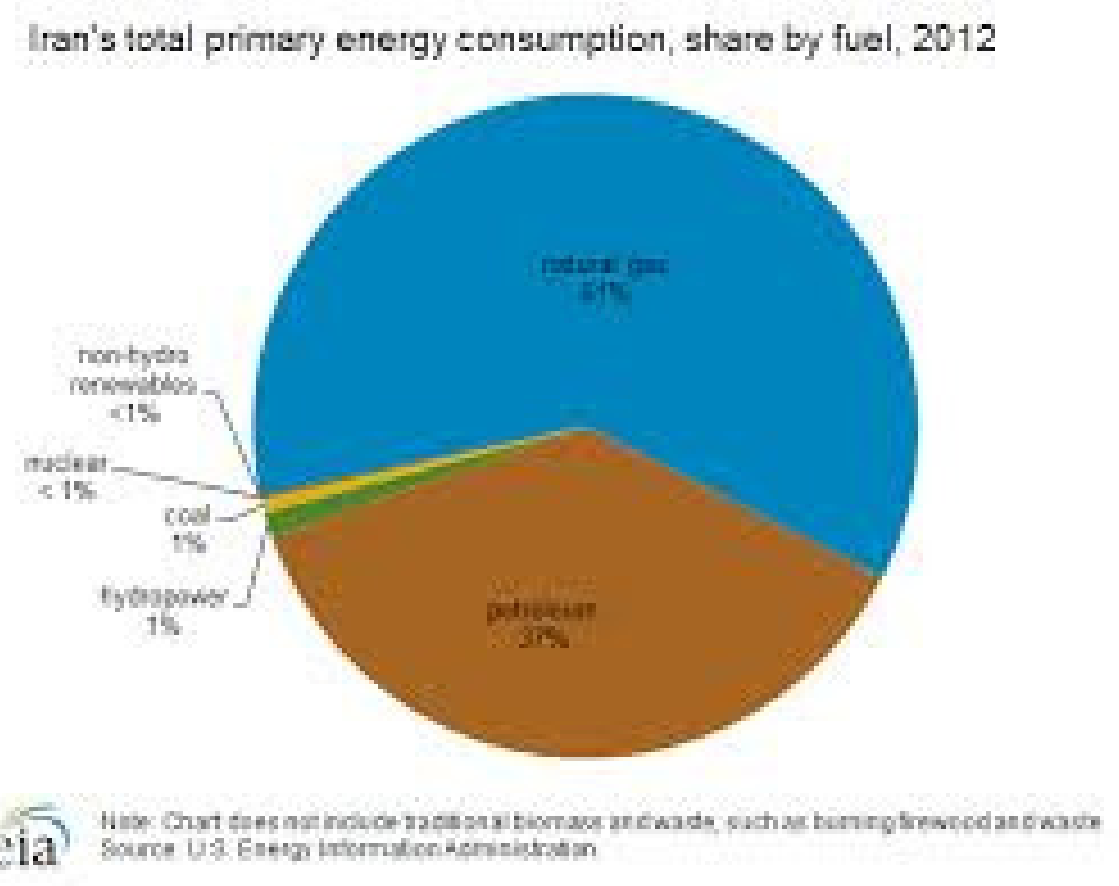

Figure 16 
One understands why an emerging economy like Iran wants atomic power. It would allow them inter alia to sell their fossil fuels on the market. But the problems for international governance of this energy policy have been most costly in terms of transaction costs. Iran would defend their position with the standard economic growth argument (de Bruyn, 2012; Eriksson, 2013).

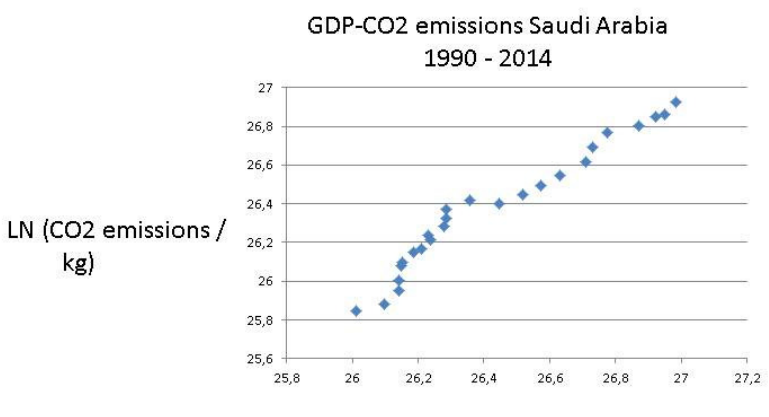

LN (GDP / Constant Value 2005 USD)

Figure 17. Saudi Arabia: $\left(y=1,03 x-0,77 ; R^{2}=0,95\right)$

The overall energy situation for this kingdom has no doubt worsened with the shale oil and gas revolution. With the idea of a HUBBERT peak gone entirely, the Saudis will not get that enormous econmic rent. In stead, they must cut down on luxurey spending and look for alternative energi sources (Figure 18). But how much will the country invest in solar parks or wind power, when oil is stil cheaper and more efficient?

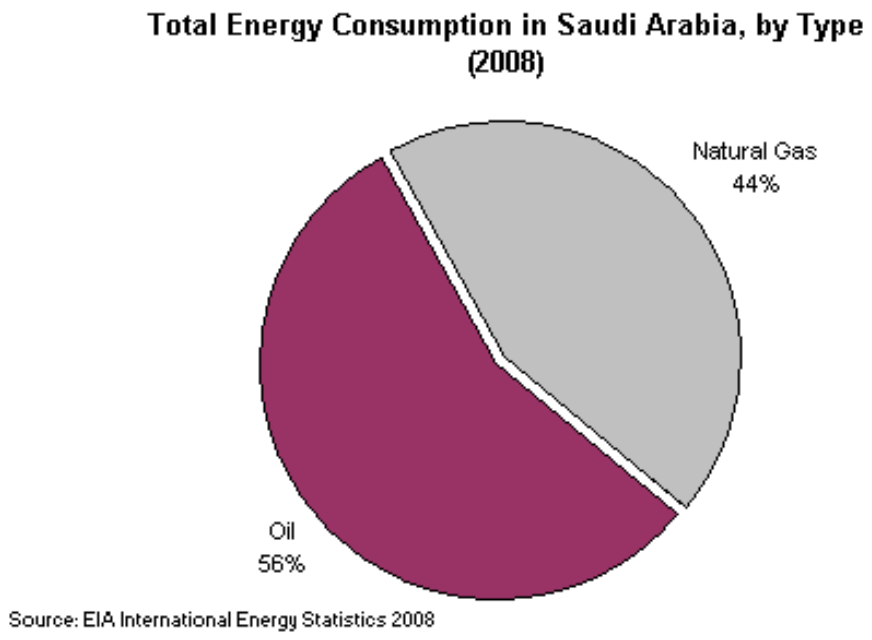

Figure 18

Saudi Arabia is a high polluter, and it needs to take COP21 very seriously, moving to solar power and nuclear investments. But it will be costly. Actually, all of the super rich Gulf states emit lots of $\mathrm{CO} 2$ per capita to maintain thei life style of massive electricity consumption per capita and pharaonic building. Saudi Arabia like other OPEC countries as well as Russia have to develop a management strartegy that takes into account the arrival of huge shale oil and gas deposits over the world and and declining rent from old type oil production and sale. 


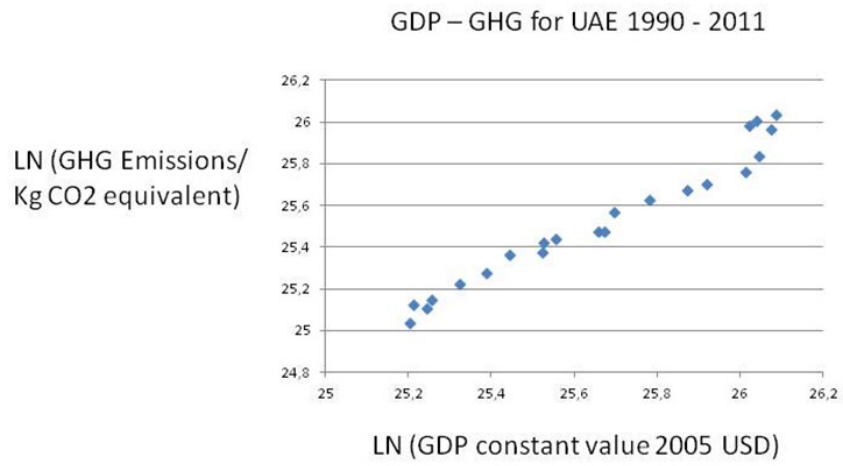

Figure 19. Unites Arab Emirates: LN (GHG / Kg CO2 eq and LN (GDP / Constant Value 2005 USD)

The UAE have increased their emission of GHG sharply in relation the positive economic development of these emirates. They rely upon the fossil fuels of Abu Dhabi with immense oil resources. Like other Gulf States, the UAE boosts with building entirely GREEN sites, with energy from solar power and almost no waste. But it is based upon their enormous consumption of electricity generated out of burning oil and gas (Figure 20). The Gulf countries use lots of petrol, gas and electricity to uphold a stunningly high standard of living, which also results in extremely high levels of emissions per capita.

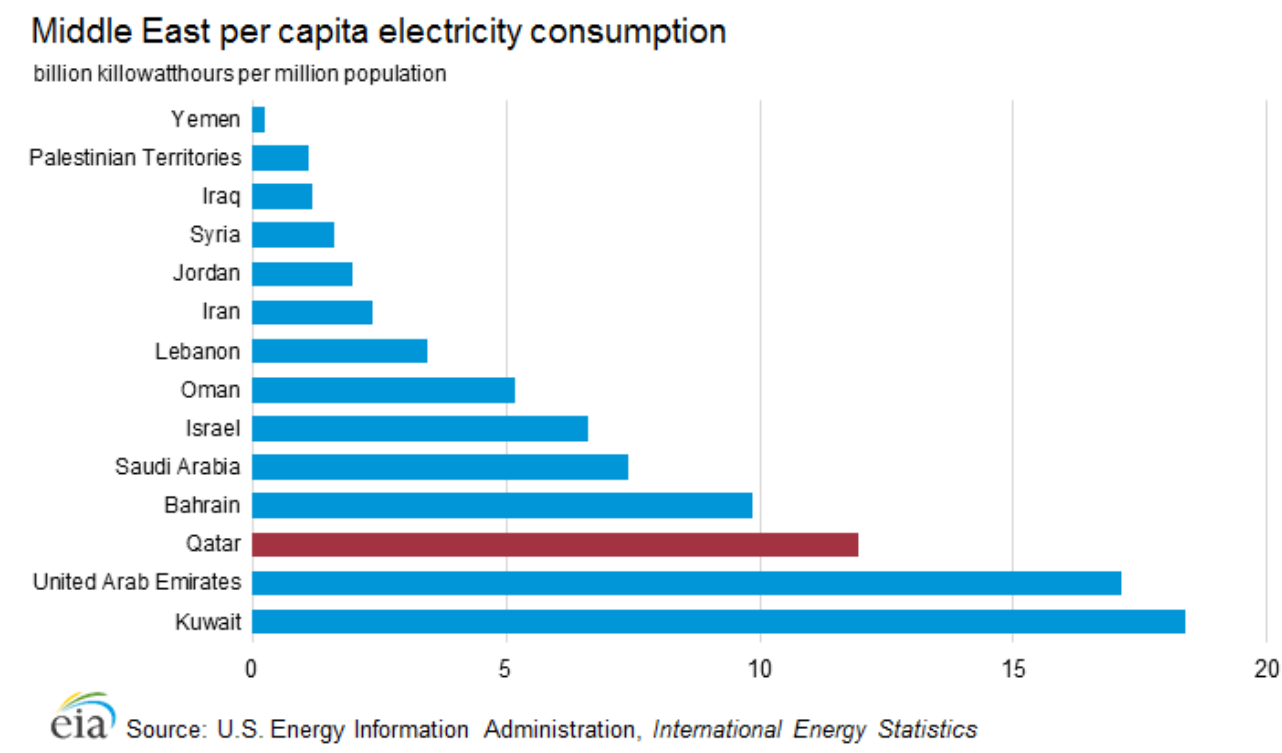

Figure 20

\subsection{Africa}

One of the promising nations in Africa is Ghana, housing both democracy and positive economic development. Figure 21 shows its GDP-CO2 picture for the last two decades, when things have gone well and peacefully. 


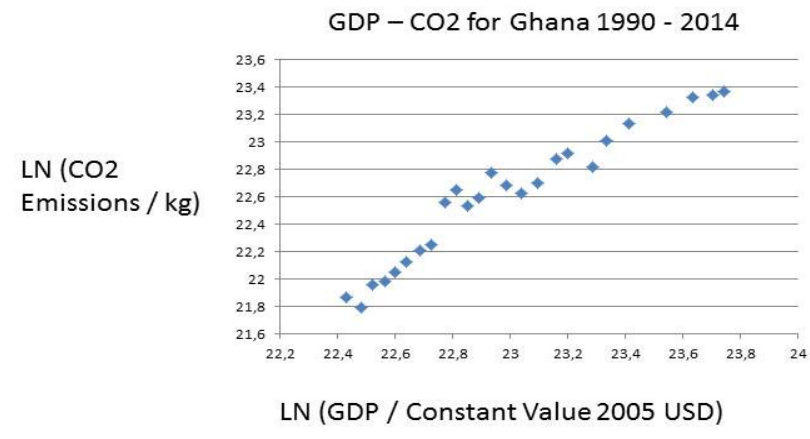

Figure 21. Ghana: GDP-CO2: $y=1,17 x, R^{2}=0,94$

There is a very strong connection between GDP and CO2 emissions in Ghana. One would like to examine its energy mix in order to understand this. Figure 22 present the energy consumption pattern in Ghana.

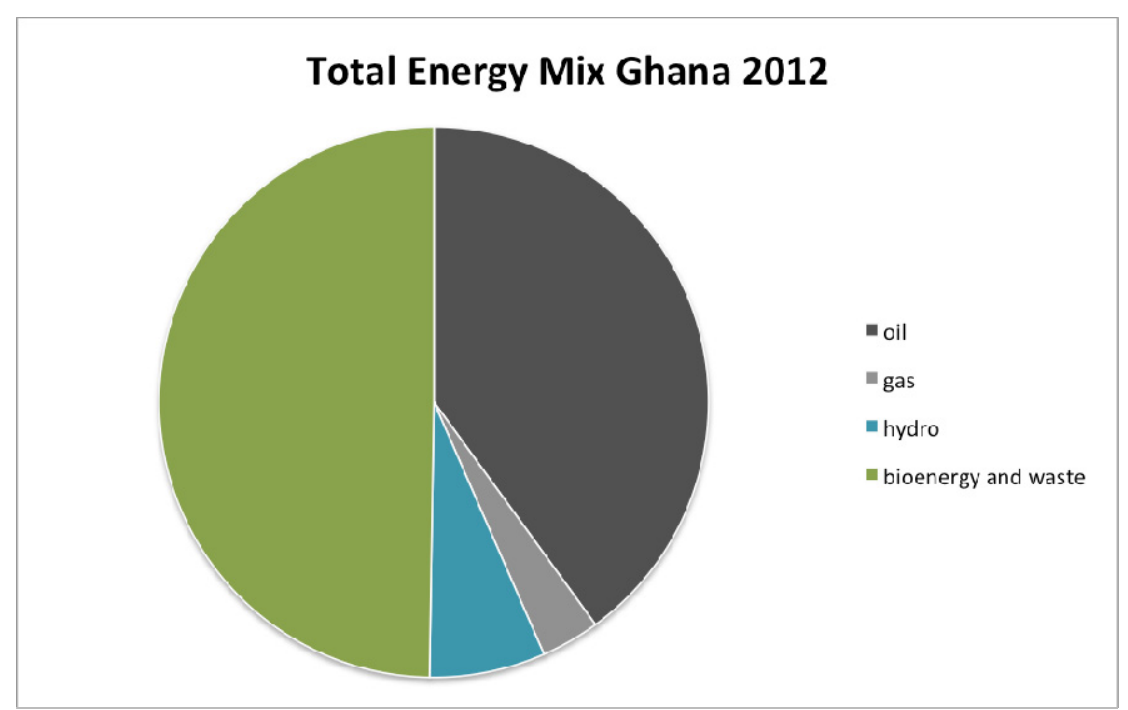

Figure 22

Source: http://climateanswers.info/2015/10/ghana-climate-and-energy-statistics/

Ghana needs both electricity in its many villages and petrol for transportation. Figure 22 shows that oil is used abundantly, but there is also much hydro power. Yet, 50 per cent of the power comes from bioenergy and waste, which is classified as old renewables. These kinds of traditional renewables are to be found in almost all sub-saharan Africa countries. And they create large $\mathrm{CO} 2$ emissions, which is why there is this close link between GDP and CO2:s here. Look now at Kenya in Figure 23. 


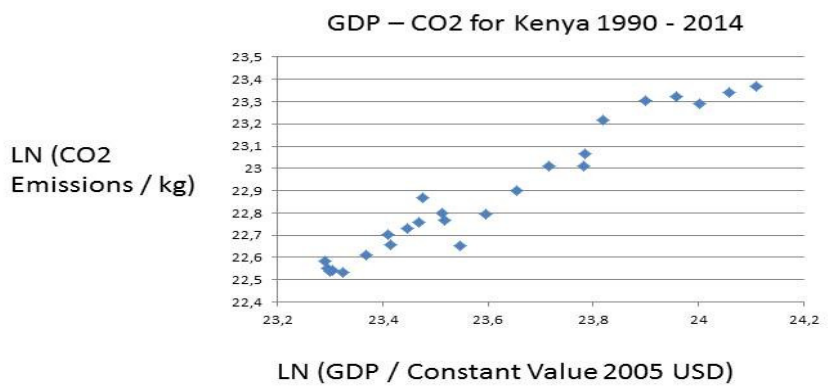

Figure 23. Kenya: $\mathrm{y}=1,08 \mathrm{x}, \mathrm{R}^{2}=0,95$

As a matter of fact, Kenya:s curve for GDP and $\mathrm{CO} 2$ :s resembles that of Ghana, both countries experiencing economic progress. The basic energy resources are also the same: renewables, hydro and petroleum - see Figure 24.

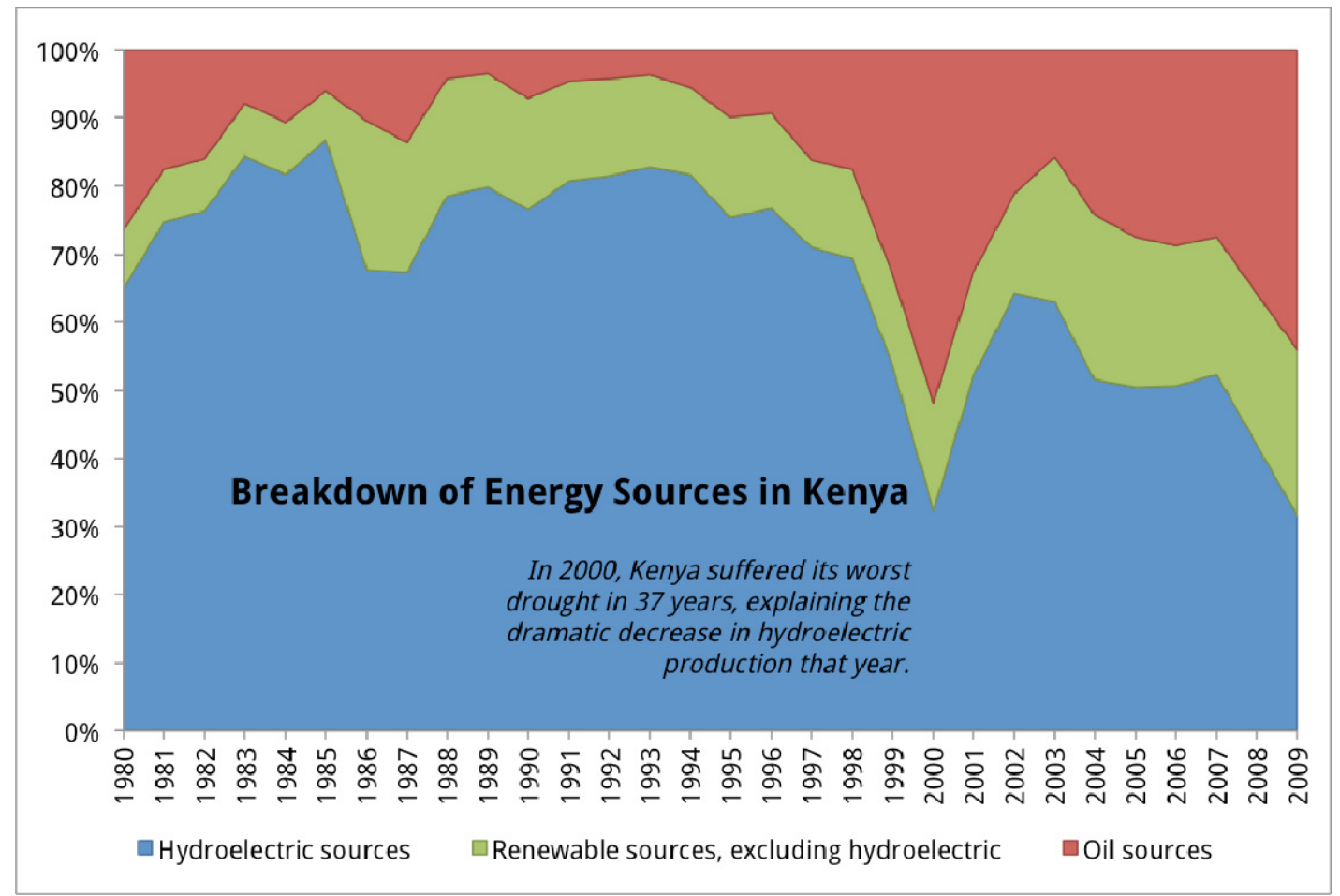

Figure 24. Kenya: energy mix

Source: http://investeddevelopment.com/blog/2012/08/energy-in-kenya-and-the 6-potential-for-renewables/

These renewables are not all carbon neutral, meaning hey include charcoal and dung besides the normal renewables like solar, wind and thermal power. One may expect that countries with the possession of big rivers resort to hydro power, like Senegal, Niger, Nigeria, Kongo, Angola and East African states. Hydro power has been launched as a solutio for several African countries to comply with COP21, perhaps helped mainly by China, building dams in Ethopia and Sudan for instance. Some say that more than 200-400 hydro power stations are to be constructed in the next decade in Africa, the Americas and Asia, but it is wishful thinking to a large extent. 
Emissions are high, because South Africa uses a lot of coal to generate electricity (Figure 25). Decarbonisation will be difficult and costly.

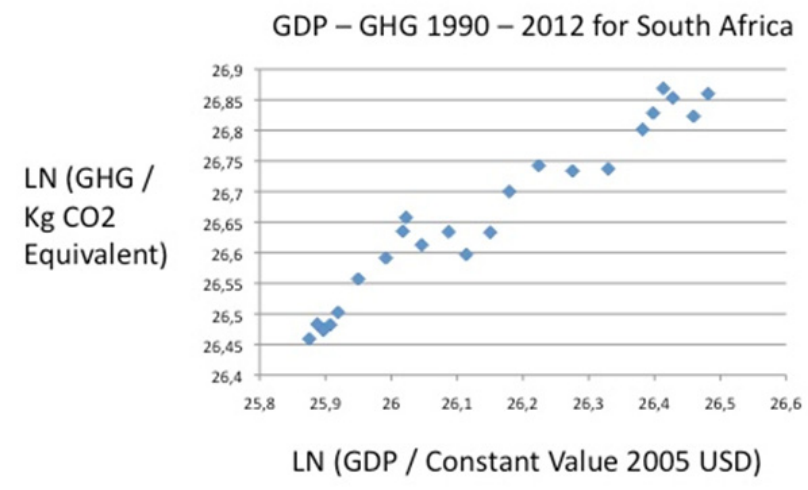

Figure 25. South Africa: LN (GHG / Kg CO2 eq and LN (GDP / Constant Value 2005 USD)

The reliance upon coal in this second largest economy in Africa is stunning.

Total Primary Energy Supply in South Africa 2012 [\% TPES]

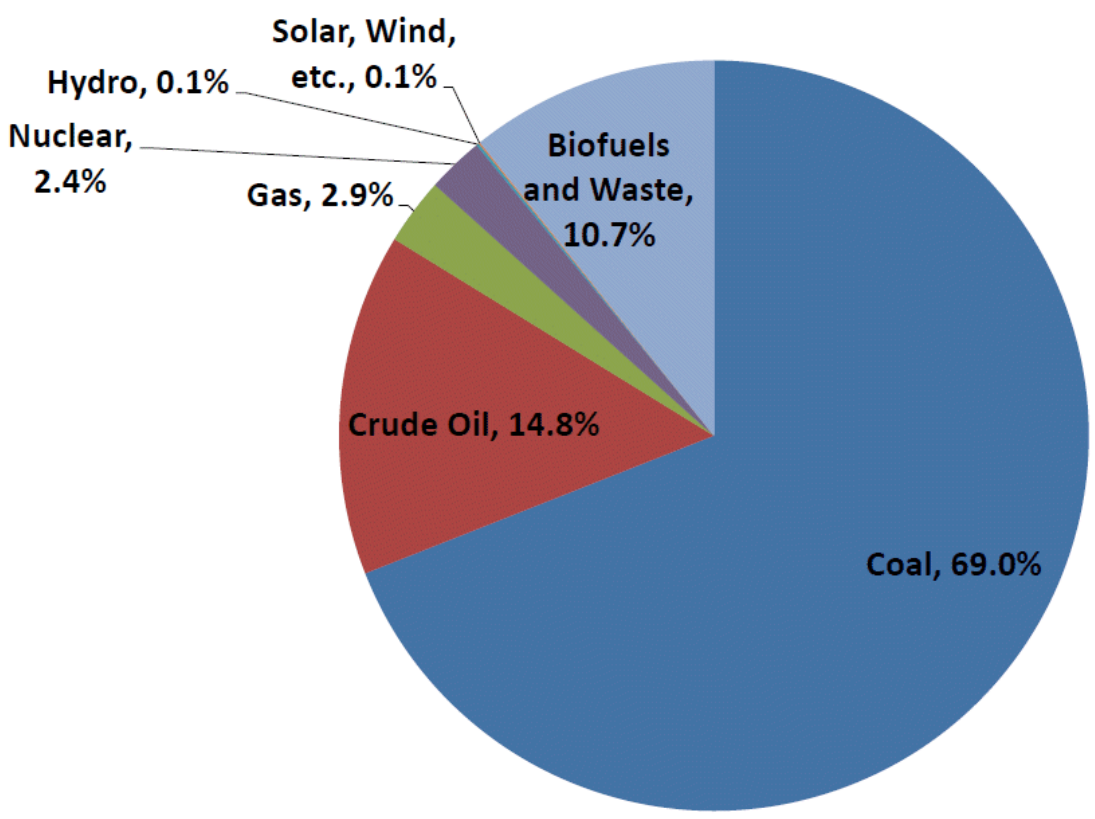

Figure 26. Energy consumption in RSA

The picture of a very close link between GDP and emission of GHG:s that is to be found with three giants in Asia China, India and South Korea - does not necessarily hold for all countries, such as Japan. This split between country predicaments for COP21 policy implementation is to be found also in the Americas. 


\subsection{The Americas}

One would expect to find huge $\mathrm{CO} 2$ emissions in this large emerging economy with lots of oil production. Countries like the Gulf States have massive CO2:s because they drill and refine oil and natural gas, burning some of it. For Mexico holds the following situation (Figure 27).

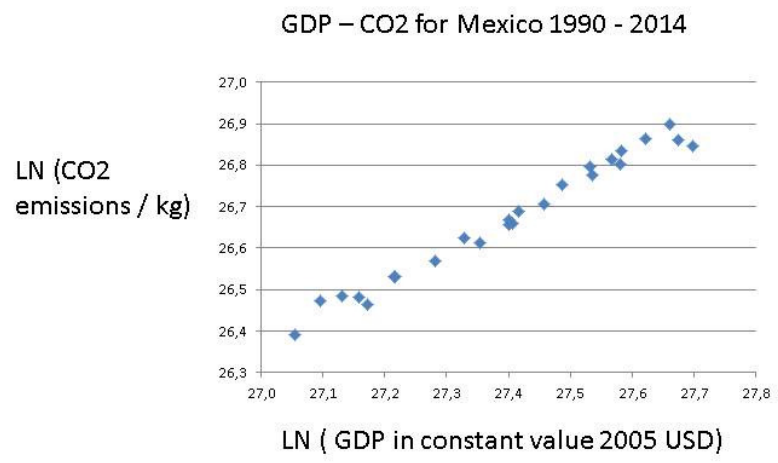

Figure 27. GDP-CO2 in Mexico: $y=0,77 x ; \mathrm{R}^{2}=0,98$

The close link between economic development and CO2 is discernible in the data, but the emissions' growth seems to stagnate in the last years. This is of course a promising sign, whether it is the start of a COP 21 inspired $40 \%$ reduction in $\mathrm{CO} 2$ :s remains to be seen. I doubt so, but let us inquire into the energy mix of this huge country that is of enormous economic importance to both North and South America (Figure 28).

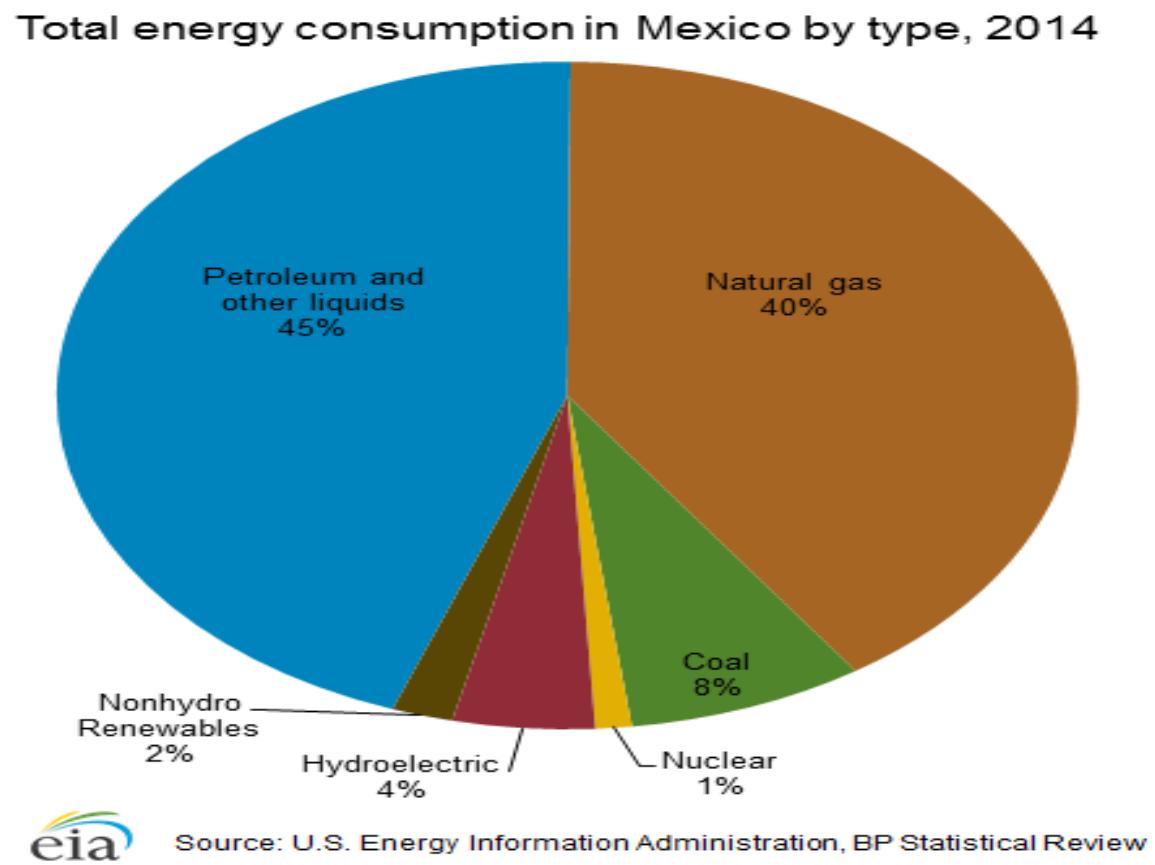

Figure 28. Energy mix for Mexico 
Few countries are so deependent upon fossil fuels as Mexico. One find the same patter with the Gulf States. The Mexican government must start now to reduce this dependency, by for instance eliminating coal and bringing down petreoleum, instead betting upon solar, wind and nuclear power. Mexico will face severe difficulties with the $40 \%$ reduction target in COP21. It has a fast growing population with many in poverty and an expanding industry sucking electricity. Can economic growth and decarbonisation go together here in a country poised for population explosion?

GDP vs. GHG 1990 - 2012 for Canada

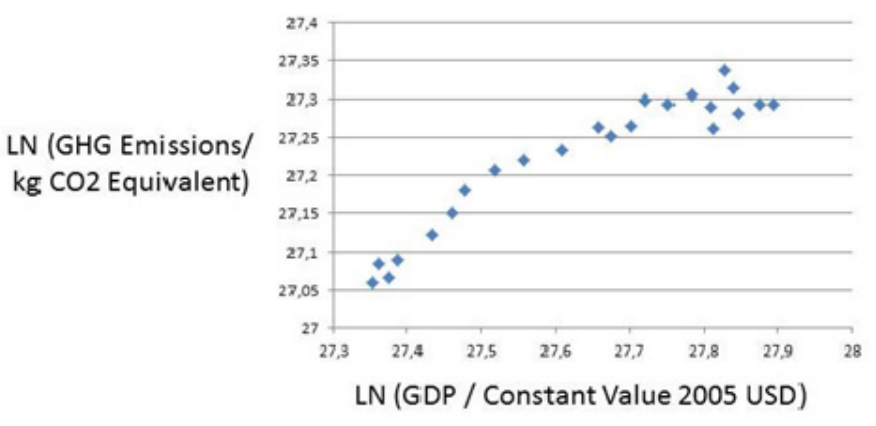

Figure 29. Canada: LN (GHG / Kg CO2 eq and LN (GDP / Constant Value 2005 USD)

Although Canada is a major emitter of GHG:s as well as one of the world's largest fossil fuel producer - oil sands, it had managed to stem the increase in emissions for the most recent years, i.e. halting the augmentation. Figure 30 may be invoked to explain this, showing a very mixed energy consumption pattern.

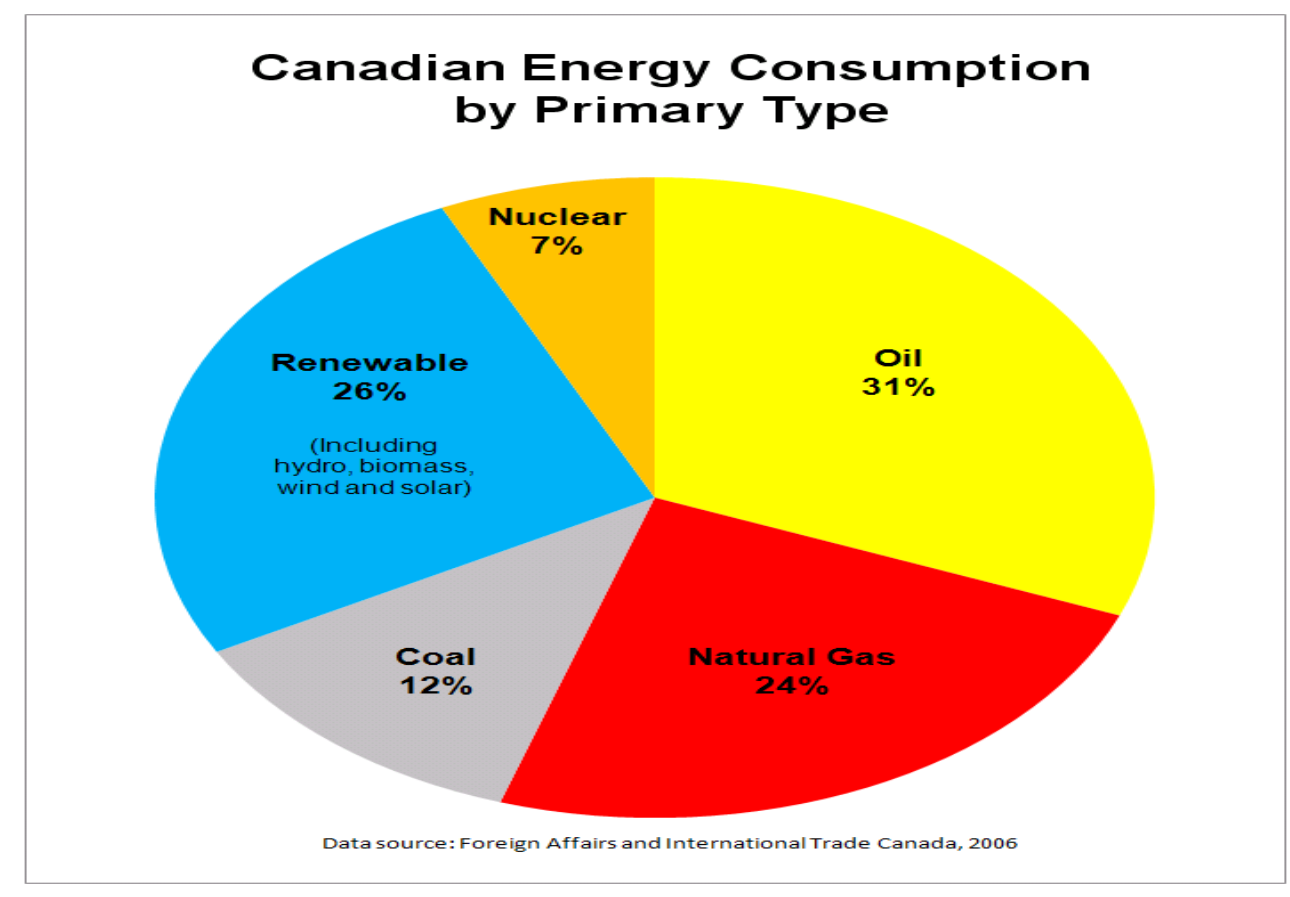

Figure 30 
Canada has a strong advantage compared with for instance China and India in that it has access to lots of hydro power and natural gas. The burning of coal is as low as 12 per cent, but oil still makes up almost a third of energy consumption.

Let us look at the ethanol country par preference: Brazil. Figure 31 shows a considerable drop in total emissions, but it is followed by huge increases that tend to flatten out.

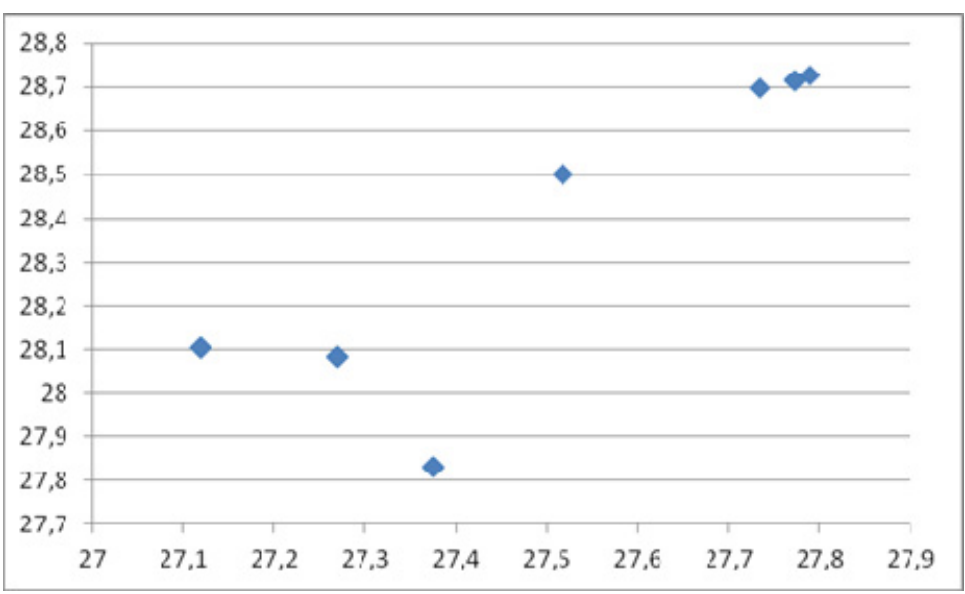

Figure 31. Brazil: LN (GHG / Kg CO2 eq and LN (GDP / Constant Value 2005 USD)

Brazil employs the most biomass in the world, but the emissions stay at a high level, which is a reminder that renewables may also have GHG:s. One advantage for Brazil is the large component of hydro power, but the overall picture for the largest Latin American country is not wholly promising when it comes to reduction of emissions. Global warming reduces the potential of hydro power, and Brazil has very little nuclear power (Figure 32).

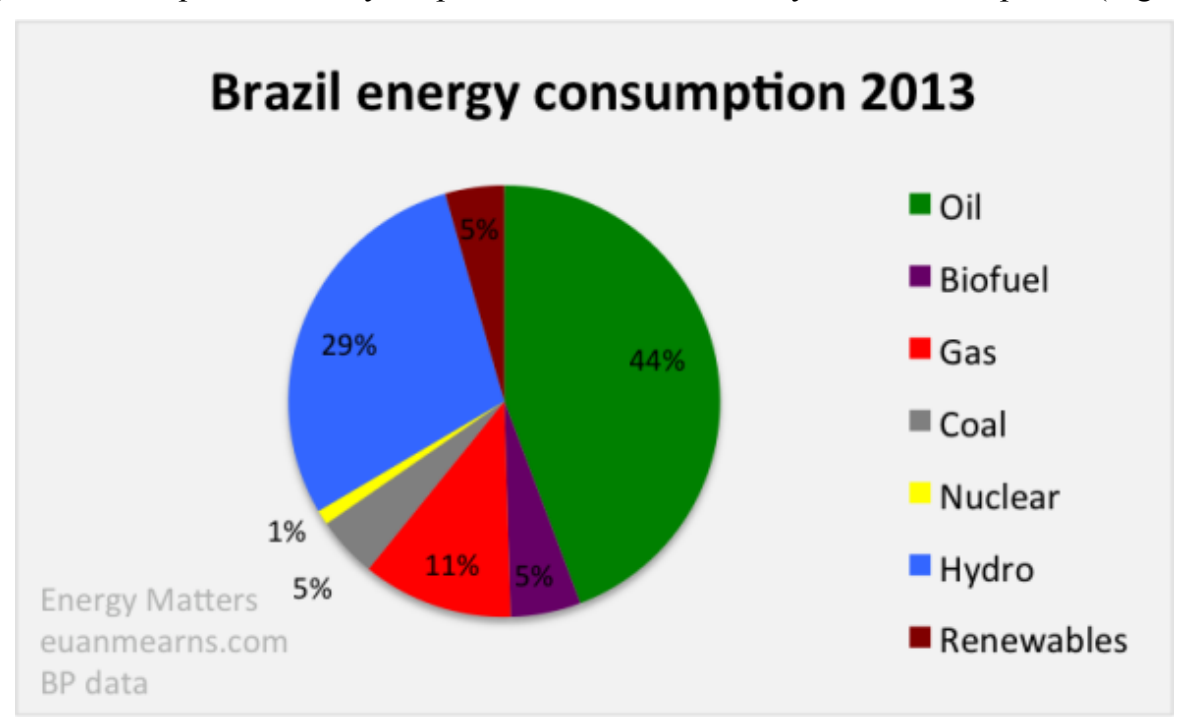

Figure 32

For most countries hold that their emission of GHG:s increases, as well as augments with the GDP. However, there are a few notable exceptions of decreases that are worth mentioning. We start with the US (Figure 33). 


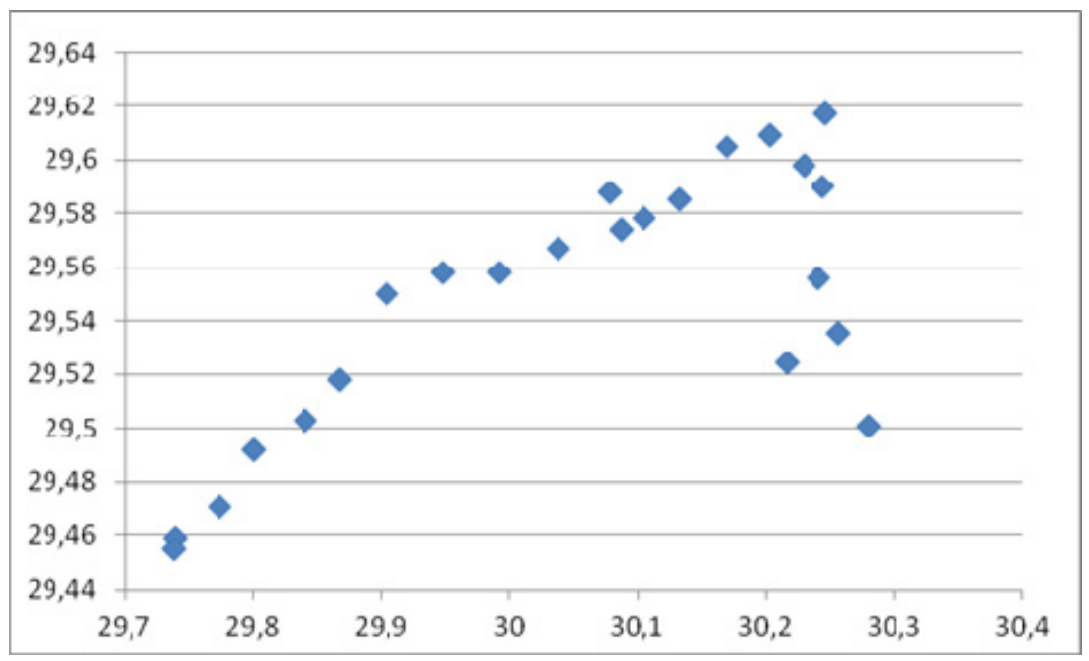

Figure 33. USA: LN (GHG / Kg CO2 eq and LN (GDP / Constant Value 2005 USD)

Recently, the level of GHG emission has been reduced significantly in the US. It reflects no doubt the economic crisis that began 2007, but the US remains the second largest polluter in the world, reflecting that it cannot draw upon a mixed bag of energies (Figure 34). Per capita GHG:s are of course extremely high for the USA. As the economy now starts to accelerate, emissions are bound to go up again.

\section{U.S. Energy Consumption by Energy Source, 2011}

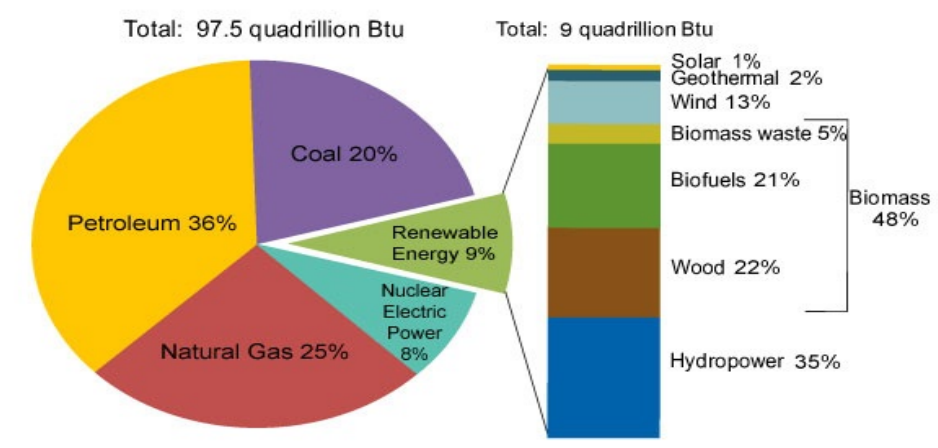

Source: U.S. Energy Information Administration, Monthly Energy Review, Table 10.1 (March 2012), preliminary 2011 data.

Figure 34

The US is heavily dependent upon fossil fuels, or some 89 per cent comes there from. What is changing is the more and more of energy is produced within the US and no longer imported from outside - the shake oil and gas revolution. Further reduction of GHG:s will meet with firm resistance from the Republican House of Congress, which may oppose the COP21 Agreement. The advent of shale oil and gas has changed the entire energy markets, lowering the price of oil most substantially. This implies not only that there will be no Hubbert peak oil for the world, but also that switching to renewable energy source will be extremely expensive, relatively speaking.

\subsection{Europe}

Another interesting country is the largest EU economy, namely Germany. Figure 35 shows a marked decrease in GHG emissions. 


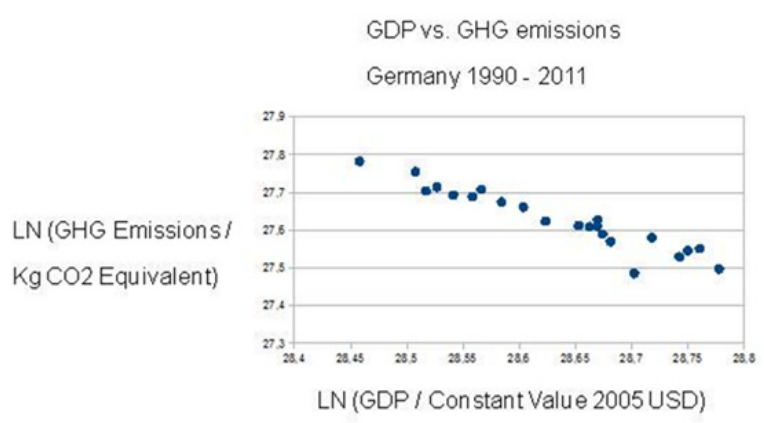

Figure 35. Germany: LN (GHG / Kg CO2 eq and LN (GDP / Constant Value 2005 USD)

The German data shows a consistent decreasing trend, which is not to be found with many countries, if at all. How come this German exceptionable policy? Germany needs massive amounts of energy, but it decided to phase out nuclear power. Can really the domestic employment of renewables satisfy this gigantic demand (Figure 36)?

\section{Germany energy consumption 2012}

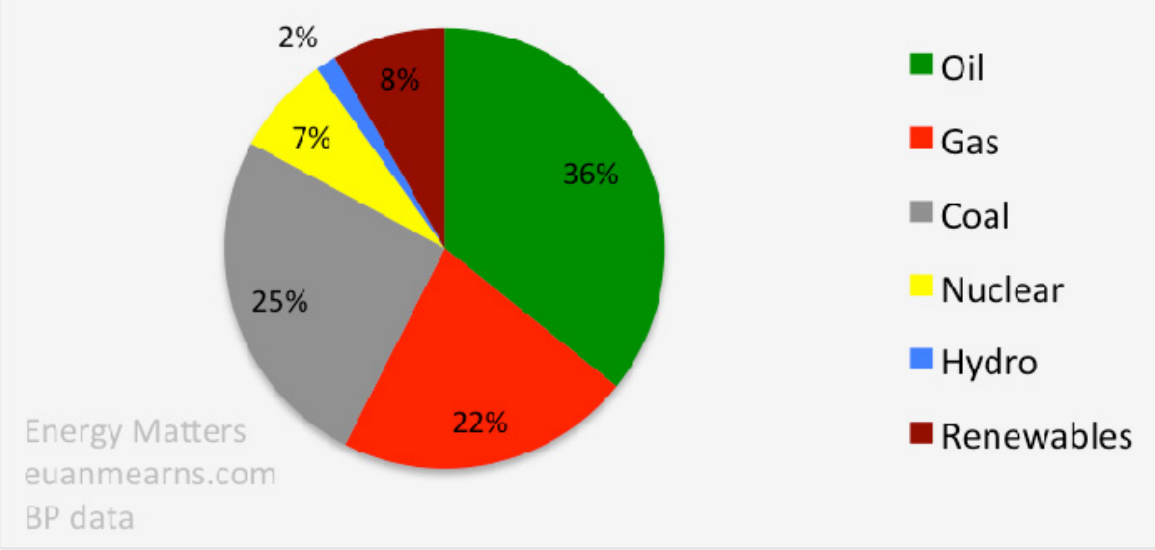

Figure 36

It is true that nuclear power and renewables has made it possible for Germany to decrease its GHG:s, but the country is still dependent upon fossil fuels, especially coal and oil. What will happen with the nuclear power stations are phased out in 2022 is that most likely the GHG emissions will start going up again. To replace nuclear power with solar and wind power will be difficult to say the least. Already, Germany uses more coal from Columbia and gas from Russia.

Finaly, let us do France with its nuclear uniqueness. 


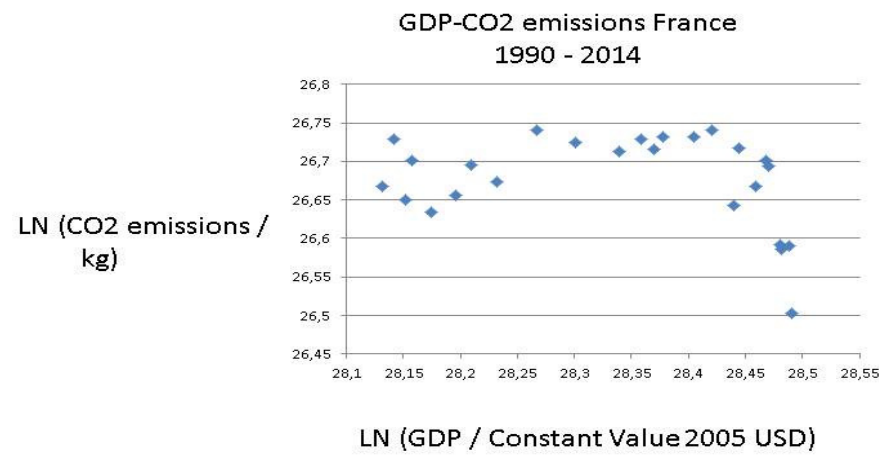

Figure 37. France $\left(y=-0,13 x+30,4 ; R^{2}=0,08\right)$

Nuclear power reduces greenhouse gases but creates another form of pollution, namley radioactive waste. The environmental movement fights both, but this may be too much. Perhaps the greenhouse gases are the worst, because they annot be contolled or burried for thousands of years? France opts fr both decarbonsation and denuclearisaton. Possible?

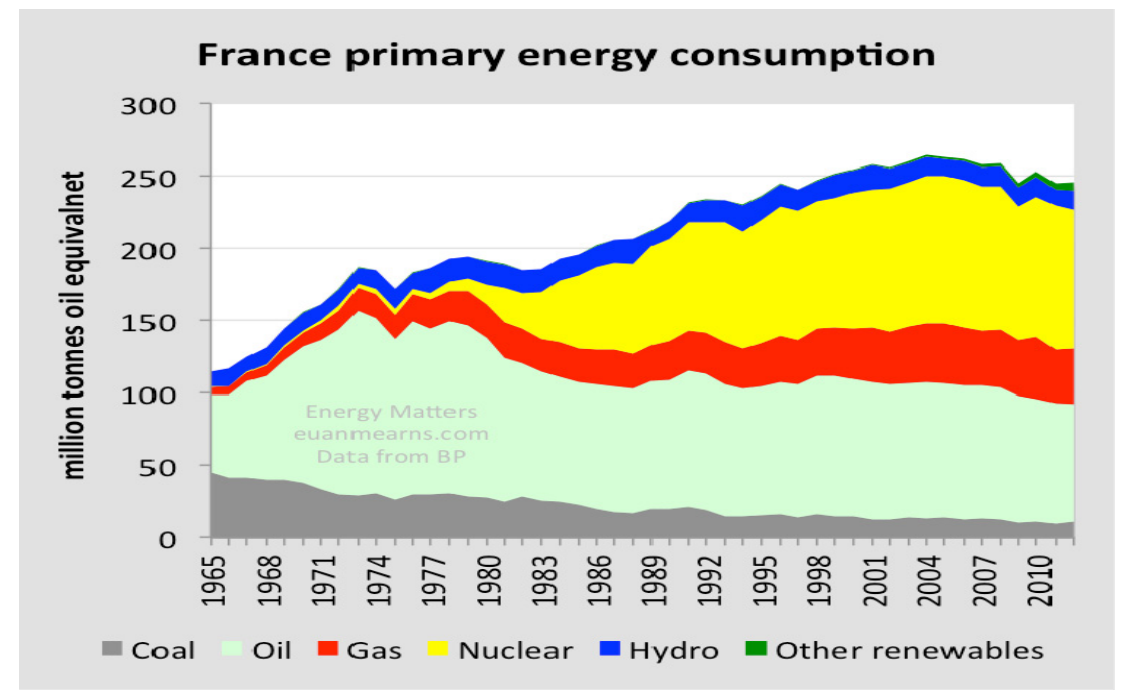

Figure 38

\section{Conclusion}

The COP21 implementation process is underway with new conferences, rising transaction costs. Some countries already declare that they can and willl meet COP21 objectives. In others, COP21 is hotely contested, like the US. Finally, as more countries fall into the Hobbesian predicament, they will not be able to contribute much, like recently Ethiopia.

Mankind is no doubt in for experiencing the natural effects of climate change, and the Third World will have the carry the brunt of the negative. The IEA prejections about future "energy needs" are not in agreement with COP21.The stylised projections for global energy needs pay no attention to COP21 implementation. They all predict upon trends from the early 21 rst century. Consider Figure 39: 


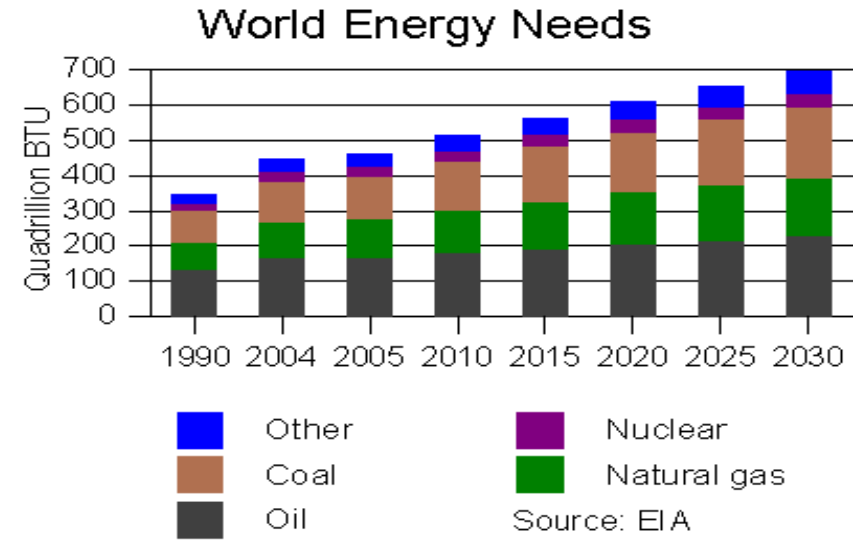

Figure 39. Energy predictions or "needs"

It should be pointed out that we are really not talking about "needs" here. It is merely standard projections from past energy "needs", viz consumption. If COP21 is to be implemented, then another management strategy for energy provision must be elaborated globally. Otherwise, the demand for economic development will trump environmental sustainability, as wind and solar power could not possibly substiture for all fossil fuels and deliver all this new energy.

Only the social sciences can inform about the incredible difficiculties to implement COP21. The step from an international agreement to effective state implementation of it is immense. The probability of implementation failure is obvious for the COP2 1 process, the biggest implementation in the history of mankind, trying to save humanity as we have come $\mathrm{t}$ know it.

\section{References}

BP Energy Outlook 2015.

de Bruyn, S.M. (2012). Economic Growth and the Environment: An Empirical Analysis. Berlin: Springer.

Energy Information Administration (EIA). (2015). Annual Energy Outlook. Retrieved from $\mathrm{http} / / / \mathrm{www} . e i a . g o v /$ forecasts/aeo/index.cfm

Eriksson, C. (2013). Economic Growth and the Environment: An Introduction to the Theory. Oxford: OUP.

EU Joint Research Centre Emission Database for Global Atmospheric.

Eurostat: Demographic Statistics.

International Energy Agency (IEA). (2015). World Energy Outlook. Retrieved from http://www.iea.org/bookshop/700-World_Energy_Outlook_2015

Mazmanian, D.A., \& Sabatier, P. A. (1989). Implementation and Public Policy Paperback. Lanham, MD: UPA.

OECD National Accounts data files.

Population and Vital Statistics Report (various years), Census reports and other statistical publications from national statistical offices.

Pressman, J., \& Wildavsky, A. (1973, 1984). Implementation. Berkeley: University of California Press.

Ramesh, J. (2015). Green Signals. Oxford: OUP.

Research - http://edgar.jrc.ec.europa.eu/overview.php

Sabatier P.A. (1993). Policy Change and learning: An Advocacy Coalition Approach. Boulder, CO, Westview

Sabatier, P.A. (1998). The advocacy coalition framework: revisions and relevance for Europe. Journal of European Public Policy, 5(1), 98-130.

$\begin{array}{lllll}\text { Sachs, } & \text { J. } & \text { (2015). } & \text { Sustainable } & \text { economies. }\end{array}$ http://jeffsachs.org/2015/08/sustainable-development-for-humanitys-future/

Sachs, J. (2015). The Age of Sustainable Development. New York: Columbia University Press. 
Sachs, J. (2015, August 10th). Sustainable Development for Humanity's Future. Retrieved from http://jeffsachs.org/2015/08/sustainable-development-for-humanitys-future/

Secretariat of the Pacific Community: Statistics and Demography Program,

Stern, N. (2007). The Economics of Climate Change. Oxford: OUP.

U.S.Census Bureau: International Database.

UN Framework Convention on Climate Change. Retrieved from http://unfccc.int/ghg_data/ghg_data_unfccc/time_series_annex_i/items/3814.php

United Nations Population Division: World Population Prospects, United Nations Statistical Division.

Wildavsky, A. (1979, 1987). Speaking Truth to Power. Transaction Publishers.

World Bank national accounts data - data.worldbank.org

World Resources Institute CAIT Climate Data Explorer. Retrieved from cait.wri.org

GDP:

OECD National Accounts data files

World Bank national accounts data - data.worldbank.org

CO2:

Energy Information Administration. Washington, DC.

EU Joint Research Centre Emission Database for Global Atmospheric

http://unfccc.int/ghg_data/ghg_data_unfccc/time_series_annex_i/items/3814.php.

International Energy Agency. Paris.

Research - http://edgar.jrc.ec.europa.eu/overview.php

UN Framework Convention on Climate Change -

World Resources Institute CAIT Climate Data Explorer - cait.wri.org 